\title{
Heterotopia of the Road: Driving and Drifting in Siberia
}

\author{
Tatiana Argounova-Low University of Aberdeen
}

\begin{abstract}
:
The paper demonstrates how car cultures in Yakutsk, north-eastern Russia, are influenced by the proximity of Japan, the country where street racing and drift driving became popular through such outlets as the manga series, animation films, YouTube and a blockbuster film, The Fast and the Furious: Tokyo Drift. These influences, which arrived in Siberia from across the Sea of Japan and Hollywood, highlight the shifting geographies and multiple cultural entanglements of the technological advancements in the global space. Through such cultural entanglements, young people in the city establish a different perception of the road, endowing it with heterotopic qualities. The article explores the heterotopia of the road in anthropology. Keywords: car cultures, drift driving, Fast and Furious, heterotopia, roads, Sakha (Yakutia)
\end{abstract}

\section{Fieldwork scene}

I was woken abruptly by the sharp screeching noise from the street. Still jet-lagged and confused in time and location, I jumped to my feet and rushed to the window. In the Arctic midnight light, I saw a white Toyota car, turning across the road, thumping music coming from the wound-down windows. Taking his time, the driver positioned his car, stuck his head out the window, spat on the road, revved his engine and shot off into the night street. A cloud of smoke and dust hung in the air behind him for a few seconds. This was not the only incident of loud screeching and music from cars during the night. Short, hot summers are busy in Yakutsk, where fast driving and street racing are part of the night social life. Throughout my stay, I was often woken by the sound of fast cars. My initial feelings of exasperation and frustration with such automobile activity were soon replaced with curiosity, interest and admiration, which instigated this paper. 
The focus of this paper is the changing culture surrounding automobility in Yakutsk, the administrative centre of Sakha (Yakutia), one of the remotest regions from Moscow, capital of the Russian Federation [Figure 1]. The republic is the least densely populated region in Russia, with just 958,500 people, and the city of Yakutsk has a population of 311,900 (Official Government Portal). The region has always had a prominent industrial and extractive profile, but while mineral and natural resources have been exported to many destinations, the transport infrastructure was complex, ineffective, and run-down. In the 1970s the quiet streets of Yakutsk, my hometown, like in many other peripheral cities in the Soviet Union, were virtually free from cars (cf. Siegelbaum 2008: 280; Pozharliev 2016: 206-207). Only in recent years has the Russian Federation government, boosted by interest in developing economic and trade relations with China, Mongolia and Japan, started improving transport infrastructure in the region. Building roads and increasing mobility created growing demand for cars (Pozharliev 2016: 207-208). The changes in the use of vehicles is evident throughout Russia, where the number of passenger cars in the last ten years almost doubled to 45 million (BOFIT Weekly). However, the transformations in car cultures that took place in the last few decades were more palpable here than in the central parts of Russia, due to the proximity of Japan. Such geographical closeness promoted the active import of Japanese-made vehicles, followed by the import of automobile fashions (Belov 2005: 133-135). 


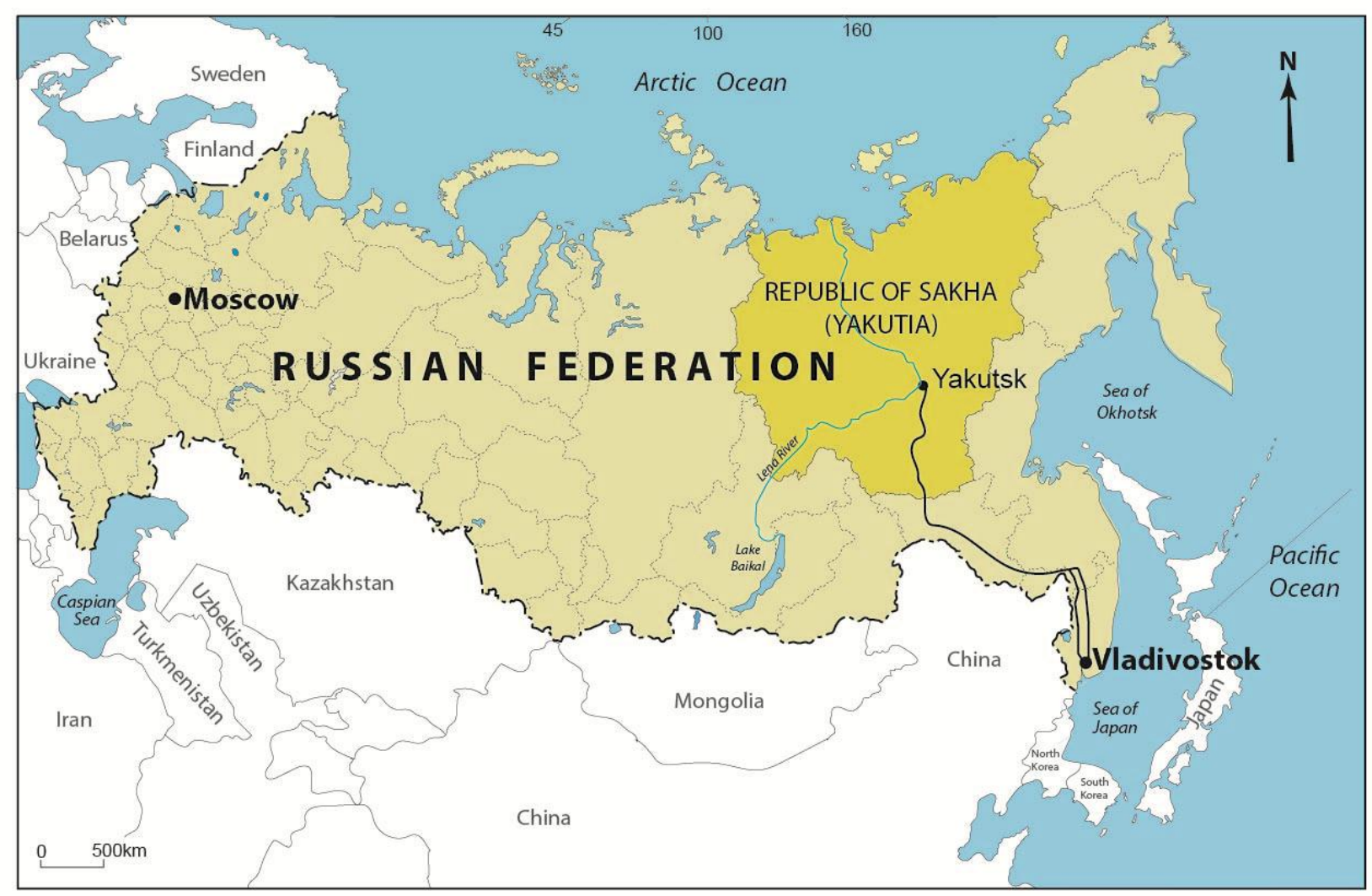

Figure 1. Map of the Republic of Sakha (Yakutia) demonstrating the proximity of Japan. (Map: Jennifer Johnston)

Nowadays, motorists can share their car passions in various automobile clubs in Yakutsk (Federatsiia), however, I focused my attention on a group of young car enthusiasts interested in honing one specific technique: drift driving or drifting [Figure 2]. Focusing on this skill highlights the influences this style of driving had on some drivers and how it has given rise to a new motoring trend. Drift driving that engages predominantly young people is, of course, an automobile fashion (cf. Sato 1991: 158) and, like all fashions, it is temporary, but that does not undermine the validity of the study. This research project does not aim to establish the longevity or brevity of this automobile activity and phenomenon. Rather, the main purpose of this analysis is to explore the processes that led to the emergence of such a driving style, providing anthropological perspective on such processes and contributing to anthropological studies of mobility and roads. 


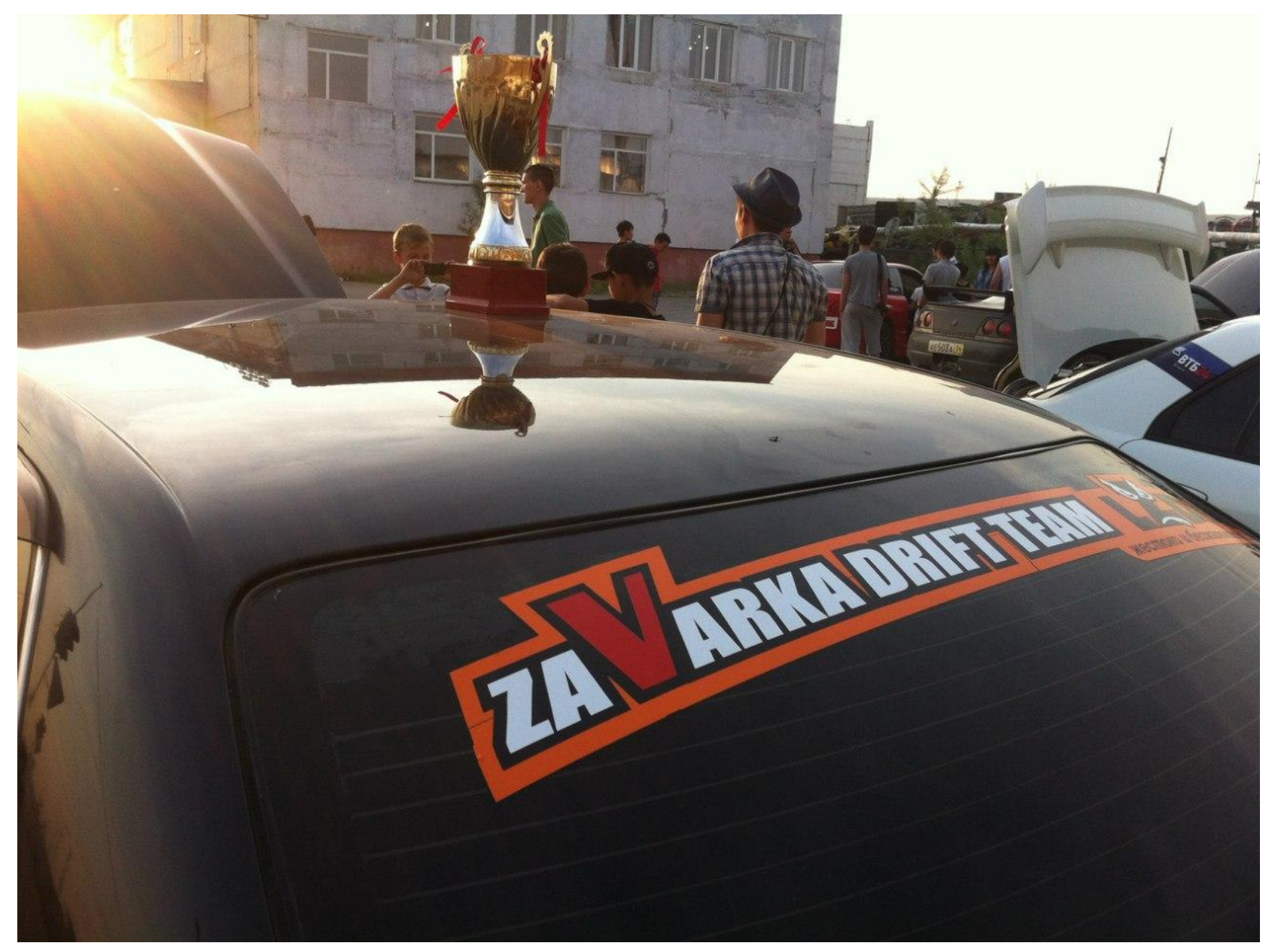

Figure 2. A competition trophy on a wining car. (Photo: Ivan Struchkov)

Using this temporal snapshot of the city automobile fashion among young drift drivers in Yakutsk helps my aim: to highlight this area of automobility study that so far has had insufficient scholarly attention (Vaaranen 2004; Vaaranen and Wieloch 2002; Redshaw 2007; Lumsden 2015). Existing scholarship that explores roads is comprehensive and ranges from the nation-state and infrastructure perspective (Dalakoglou 2010; Dalakoglou and Harvey 2012; Dawson 2015; Harvey and Knox 2012; Harvey and Knox 2015; High 2009) to film studies (Archer 2017; Eyerman and Lofgren 1995; Mills 2006). This paper contributes a complementary spatial perspective that adds a phenomenological dimension to the emerging anthropological concept of roads. It also contributes to the discussions of contemporary mobility in Russia (Popov 2013; Kruglova 2019), moving attention beyond the centre and western parts, towards its peripheries. I invite the readers to explore the road phenomenon as relational and social spaces and, following Harvey and Knox (2012, 2015), Dawson (2015), I 
argue the road is more than a space used for transport and infrastructure: it is a space of social engagement. Roads are soft infrastructure (Gallan 2015; Landry 2006) and a space conducive for imagination and creativity.

To examine these aspects and transformations, I carried out ethnographic fieldwork every summer between 2011 and 2015. I interviewed young people aged 18-30, predominantly men, city residents, representing the three drifting clubs in Yakutsk, and other young people who did not belong to clubs, but engaged in car racing and stunt driving. All interviewees were from regular families of average income and had to keep jobs to continue with their hobby (cf. Vingilis and Smart 2009: 151). I held non-structured interviews, conducted observations and collected relevant data from social media, such as Facebook, WhatsApp, VKontakte, and local periodicals. I attended racing sessions, formal and informal competitions, and gatherings of club members. The passion and interest with which these young car enthusiasts talked about drift driving were infectious and sustained my enthusiasm for this research project.

I will first address the phenomenon of drift driving, its origin and illustrate the influence the Japanese car industry had on the development of the automobility in Sakha (Yakutia) and how the motor fashions travelled from Japan to Yakutsk together with imported second-hand vehicles, media and film influences. I provide a retrospective look into the development of car cultures in Russia that will help the reader understand the current automobile situation in the region.

I then discuss the cinematic experience and a blockbuster film, The Fast and the Furious: Tokyo Drift, that inspired young people in Yakutsk to take up drift driving and racing and foster unique relationships with their cars. I argue that although originating and rooted in a different cultural context, car driving styles and fashions were transported to a different cultural setting, appropriated and adopted to fit the needs of the car users in this remote region. In the process of imitation, I argue, young drivers experience freedom in the otherwise heavily controlled and regulated spaces which roads are. And in this process, I claim, the road emerges as a space with different qualities, which allows me to ask whether the road might be conceptualised as heterotopia, as discussed later. While for many people heterotopia normally remains a cinematic experience, the drifters in Yakutsk actually engage with the heterotopia of the road. 


\section{Drift}

Sean Boswell: Drift? What do you mean drift?

[Some shiny cars effortlessly glide in front of both men]

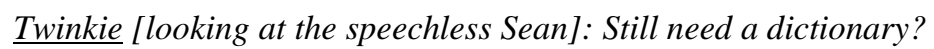

(The Fast and the Furious: Tokyo Drift 2006)

This scene in the blockbuster film, The Fast and the Furious, takes place in the multi-storeyed car-park where Sean, who recently arrived in Tokyo, is being introduced to drift driving. This dialogue between two protagonists in the film captures the essence of what drift is about; it is hard to describe but it is very powerful in its visual effects. Drifting is a driving technique in which the driver turns the vehicle in a controlled manner and causes intentional oversteering of the vehicle while maintaining speed. As a result, the car 'glides' on the smooth surface around the corners [Figure 3]. Drifting is a combination of sumo wrestling and figure skating multiplied by the time factor as described by one Japanese sportsman (Katsu 2003). A quote from my field notes captures the sensory element of drifting (cf. Waitt, Harada, Duffy 2017: 4).

Ivan: 'Drifting is not just for fun, it is a sport. There is everything: adrenalin, smell of burnt rubber, screeching noise, and clouds of smoke'. As Ivan describes this, he pauses, and a broad smile appears on his face. At this moment I realise that in his mind he is there, on the road, enveloped by excitement and electrifying sensation. 


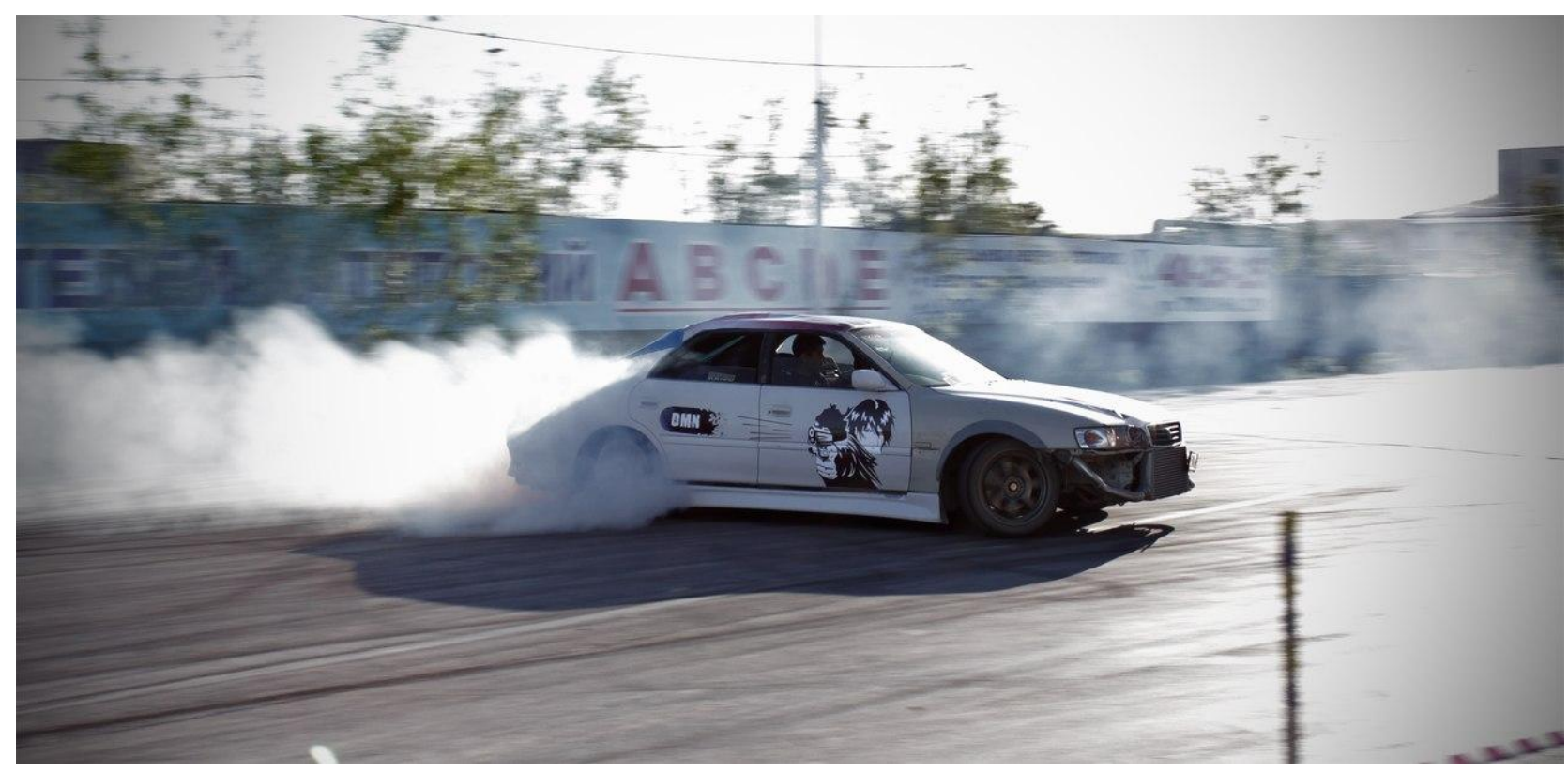

Figure 3. A drifting car on the racing track (Photo: Ivan Struchkov)

The technique of drifting emerged in the 1960s from illegal racing along the hilly landscape touge (峠) in Japan and soon was established as a driving fashion. The popularisation of this kind of sport is associated with the name of Keiichi Tsuchiya (since proclaimed the Drift King or DK), a street racer in the past and a professional racer who came to fame in his legendary Toyota Corolla Levin AE86. Drifting became popular and soon this style of driving was introduced in the urban areas of Japan and, before long, it was recognised as an official sport with regular events all over the country. The growing interest in this technique and the skill of drift driving inspired manga, the comic series Wangan Midnight (Kusunoki 1993) and Initial D (Shigeno 1995). The genre of this manga, known as supokon (スポ根), from スポーツ [supo:tsu]—'sport' and 根性 [kondze:] — 'will power'), revolves around sporting ambitions and achievements, overcoming difficulties and opposition in everyday life. The main hero of the Initial D manga series is a young man determined to win drifting competitions. The culmination of such manga is usually an important sporting event, in which the main characters win (Roth 2014: 97). Later, the theme of the skill and spirit of racing was turned into animated and feature films that proved to be very popular with young audiences.

Boosted by cartoons and the internet, drifting became trendy, and quickly spread from Japan to Australia, Malaysia, Europe and the USA. In America, fascination with drifting became a part of a series of action films 
The Fast and the Furious. The third film in this series was called Tokyo Drift (Universal Pictures 2006). The plot of the film, similar to the supokon storyline, is about a young man called Sean Boswell who, to avoid imprisonment, is sent from America to his father, residing in Tokyo. Here Sean is introduced to the underground world of fast cars, and gradually acquires drifting skills which are necessary to stand against the yakuza gangsters. The film is filled with roaring engines, speed, beautiful and sleek cars. There are plenty of breathtaking scenes of cars floating along famous suburban hilly districts and pirouetting in the multi-storey parking lots in urban Tokyo. Released the same year in Russia with the title Forsazh, the film ended with a warning: 'The motor vehicle action sequences depicted in this film are dangerous. All stunts were performed in controlled environments with professionally trained stunt crews on closed roads. No attempts should be made to duplicate any action, driving or car play scenes herein portrayed'. These warnings had no effect on the viewers whatsoever, and drifting was embraced by young people in many parts of Russia almost instantly. The film served as an inspiration and an invitation to explore the world of drifting (Shevchenko 2019).

In Yakutsk, too, the response was swift; a group of drifting enthusiasts led by Danil started a drifting club (1). The team consisted of young people who shared their passion and practised drifting and sport racing in their free time. Danil, a successful contestant in the local and regional competitions, described the main aspiration of the club as the development of drifting and racing skills and participation in the competitions at the Russian Drift Series organised in Far Eastern Russia, and in Yakutsk (Russian Drift Series). Danil wants drifting to be perceived as sport rather than simply dangerous driving on the roads:

Of course, we all like to have a ride in the town and this is OK, this is life. We taste life better if we do what we love doing, and it is very cool that we can afford doing that. At the same time we are all members of the team, like a team on the ship, which means we are all responsible for a mistake (kosiak) of one member.

Many racers came to drifting through their interest in video gaming. I was introduced to Valentin, the champion of many drift races and a car enthusiast. Valentin came to an interview with me at a café during his lunch break. Dressed in a business suit, crisp shirt and tie, it was hard to recognise in this professional-looking man a passionate drifter. He described how he got into drift driving: 
My passion for car racing started with video games. I spent many hours at the racing machines in the games arcades after school. When I sat down behind a real steering wheel, the skills I gained from video gaming came in useful. I do car racing and drifting as a pilot and co-pilot. My job in a bank is not my future career, it just pays my hobby well, but my real dream is to get to Silverstone (2) one day.

For Danil, too, the way to drifting was through video and films. He explained: 'Why did I get into drifting? Because I got infected with the driving bug (zabolel vozhdeniem). I watched films, the internet, Forsazh and other films. Beautiful pictures. Different life and I wanted to be in there. I had a motorcycle to start with; it got me hooked on mechanics. I then bought Nissan Silvia S13 and it went on from there.' Some drivers simply learned it early. Misha, 20 at the time of the interview in 2015, was already an experienced driver. His interest in driving started from helping his father in the garage: 'Dad would be under a car fixing it and I would pass him wrenches and keys. He taught me to know the car inside out and taught me to drive when I was 12.'

Like Valentin and Danil, many people in the racing clubs in Yakutsk have sporting ambitions, but there is little opportunity for them to pursue their aspirations. Often drifting enthusiasts complained about the local authorities who do not support their interest. Lack of facilities in Yakutsk forces drifting teams to explore other possibilities [Figure 4]. One spring evening, I met drifters from one city club in a fast food café. I was glad to see most of the team arriving in their competition cars (boevye mashiny) with their girlfriends, who shared their partners' passion but did not drift drive themselves. While we were sitting around the table covered with vinyl tablecloths, sipping Coke from tall paper cups, the team members enthusiastically informed me about their ambitions, planned championships and desires for good racing tracks in Yakutsk. After a long friendly chat and an exchange of jokes and stories, we drove to Komsomol'skaia Square, a large open space, at the edge of the city. From the back-passenger seat in the car that drove last in the long chain of vehicles, I could see how large exhaust pipes were throbbing while waiting at the lights, and how their powerful engines pulled the cars forward as soon as the red light changed to amber. 


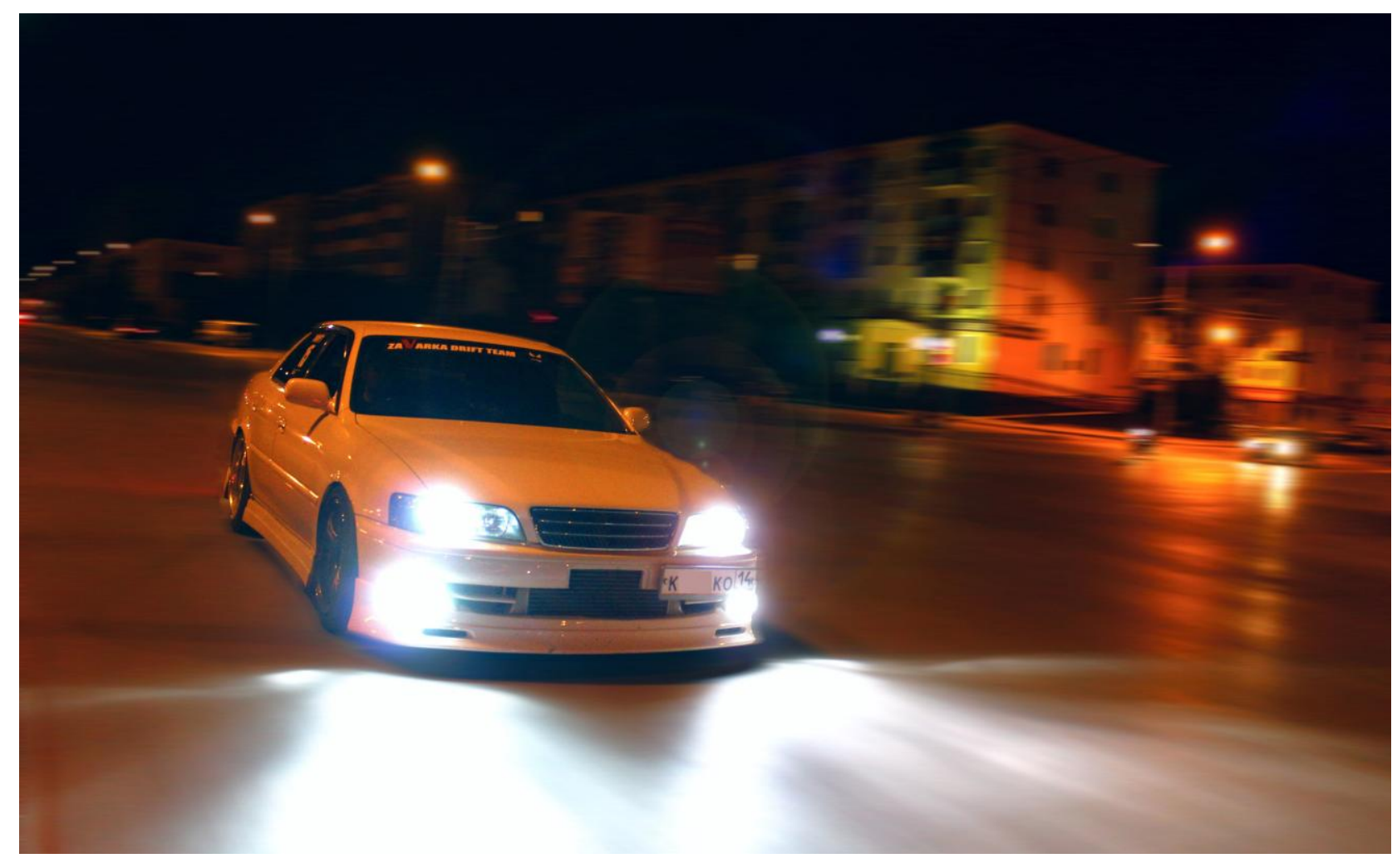

Figure 4. On the way to a drifting session. (Photo: Ivan Struchkov)

The square was almost empty on our arrival; the team practised for a while and flaunted their skills while pirouetting and scorching the tarmac, the circular black tyre marks and clouds of smoke tracing their energetic movements. A few passers-by stopped to watch the drifting cars, their faces filled with a mixed expression of awe for the skill and the improbable control over the car, and a fear of the force with which the roaring engines were cutting through the air and smoke at full throttle.

It soon became obvious these drift drivers were restricted in how much drifting they could perform. Their gatherings were sometimes arranged semi-officially and often covertly (cf. Sato 1991:13). After an hour of spectacular demonstration and discussion of the adjustments to suspension, followed by the customary inspection under the bonnets, we fled from the square: 'Road police will be here any minute,' I was told. Freedom for drifting had shrunk to 60 minutes and we headed off for another ride in a different part of the city not equipped with CCTV cameras. The sky gradually grew dark velvet and the city, sleepy at the end of the long working day, was getting ready to go to bed. 


\section{Car cultures and mobility}

Car owners were a marginal group throughout the history of the Soviet state from 1929 to 1991, where a car was a luxury item, a dream, and certainly unattainable for many (Siegelbaum 2008: 238). The shortage of cars in private ownership, and a shortage of cars generally, resulted in a lack of demand for good roads. In 1928, according to one source, roads in the Soviet Union were the emptiest in the world (Siegelbaum 2008: 280). The roads remained empty for several more decades.

John Urry (1999) suggested automobility plays an important role in the democratisation and modernisation of society. He further argued, together with his colleague Mimi Sheller, that civil societies are 'sets of mobilities flowing over roads which have only been civilianised as more and more social actors have demanded rights of personal mobility' (Sheller and Urry 2000:743). The gradual deterioration of the socialist economy (Verdury 1996: 30-38) and consequent introduction of market relations were leading to the collapse of the collectivist system. Development of automobility was a parallel and gradual process, as Pozharliev (2016) attests. But it was this process of development of mobility and automobility, the use of private cars, that accelerated development of individualism and assisted the inevitable collapse of the system (Siegelbaum 2008: 248). The downfall of the Soviet Union in 1991 was an opportunity for increased automobility. At the start of the millennium, a car became a crucial possession for ordinary households and an important element of the quotidian use that drove away from the Soviet socialist economy and culture.

When analysing a transformative change in growing movement and mobility, the development of roads and an increasing number of cars in post-Soviet Russia, these changes can be compared with post-war America and the opportunities for movement and mobility that opened there after World War II. Jack Kerouac's acclaimed novel On the Road, where Sal Paradise and Dean Moriarty bond on a long trip, describes these opportunities through driving and engaging with the road (Kerouac 1957). Kerouac's novel 'presents North American roads of the late 1940s as granting deliriously liberating social, sexual, philosophical and spatial freedoms' (Larson 2009: 35). The travelling of Sal and Dean in their old car opens new encounters and discoveries and represents a spirit of rebellion towards the dominant authority. Movement and mobility in the novel highlight major 
themes of resistance and freedom in Kerouac's book. Kerouac confronts an America that does not approve of mobility, non-conformity, a country that is parochial and sedentary, one that presents a 'place-bound rooted world' (Cresswell 1993: 260).

The American transition to greater automobility is comparable to the post-Soviet experience in the late 1990s that echoes a getaway from the rigidity of the system of state control, frugality, and enclosed ideological and physical space (Siegelbaum 2008: 213). The enclosure of the Soviet country that for many decades denied people's mobility for ideological reasons, finally made travelling abroad possible. Road conditions and infrastructure were improving; a state monopoly on all transport systems was fading away. Sedentarism imposed by the state disappeared and public mobility, previously suppressed, was increasing. Transportation inside the country got faster and easier (Popov 2012).

The transformation of the post-socialist Russia and the growing fascination with speed, comparable with experiences in post-war America, evoke the notion of freedom of the individual. In both settings, the desire and longing of people to experience unrestricted movement is intensified by vast spatial expanses that could potentially deliver new experiences of physical movement and mobility, and freedom, however limited and illusory (Dawson 2017b: 9; Lefebvre 1971; Poster 2002). The car becomes a crucial element in this experience, and a powerful expression of individualism. For generations of people who were brought up in the Soviet era with the idea of property as a communal realm, the move to private car ownership was a significant one. This move is also the most celebrated one, judging by the growing number of car enthusiasts, automobile clubs and younger drivers who are joining the automobile culture.

In his eschatological work America, Jean Baudrillard (1988) compared public spaces that are sanitised of deep historical connotation, not rooted and deliberately cleared of meaning, to deserts. With reference to the American landscape, Baudrillard proposed a notion of 'desert speed' (1988:5), by which he refers to an increased amount of driving, faster pace of life, pushed by automobile cultures and characterised by practicality, pragmatism, reduced engagement and diminished sensitivity. Such fast tempo of life and driving helps to discover the new and forget the old, states Baudrillard (ibid.). When certain memories turn into clutter, increased mobility and driving 'produces a kind of invisibility, transparency, or traversality in things, simply 
by emptying them out' (Baudrillard 1988: 7). In contemporary Russia, the notion of 'desert speed' can be applied to the government's attempt to rewrite the awkward Communist history and get rid of memories that create debris and impede the progressive image of the country. Motorways and public roads become places sanitised of memory and, therefore, 'amnesic' (1988:7). 'Driving is a spectacular form of amnesia. Everything is to be discovered, everything to be obliterated' (Baudrillard 1988: 10). This significant characteristic of driving echoes the contemporary ideological endeavour to use the vast landscape as an opportunity to revise and amend the socialist history and the Communist past of Russia. The contemporary Russian landscape presents a canvas for rewriting histories. Ideas of modernity fit perfectly in this scenario, where greater mobility is opposed to the enclosure of the Soviet space, where moving cars, speed, flow, fluidity and progress are opposed to the stagnation of the Communist era, and where roads are opposed to roadlessness (ArgounovaLow 2012b).

Another point that highlights a correspondence between Russian and American experiences of increasing mobility is the importance of cinema in America, where culture is about 'space, speed, cinema, technology' (Baudrillard 1988: 110). Baudrillard takes it even further by stating that in America 'it is the whole of space, the whole way of life that are cinematic. The break between the two, the abstraction which we deplore, does not exist: life is cinema' (ibid.). In the Soviet Union and post-Soviet Russia, too, the role of cinema has been palpable. For a long time cinema had been a projector of the outside world, providing glimpses of the external reality for those who remained inside the country without opportunity to travel abroad. Cinema continued to be a channel for new trends, fashions and influences, as this example of The Fast and the Furious: Tokyo Drift illustrates well. The research participants with whom I worked continuously referred to films, actors and sportsmen familiar to them from the screen. They often recited chunks of dialogues from films and videos they knew by heart. It made me aware of the powerful role the cinema had on popularisation of drifting among young people in Yakutsk. The virtual reality of the screen turned into reality 'through the strange destiny of simulation' (Urry 2000: 62). Through the screen came the knowledge of various brands of cars and certain techniques of driving, but mostly it was the atmosphere of driving, competing, and appreciation of speed and space that affected drift drivers. The extent to which this reality is taken from the screen and transferred to life deserves some discussion. 


\section{Domestication of the Dream}

'Drifting, like all cars and car fashions, arrives to Yakutsk from Japan. Straight from there', says Ivan, who, like many of his pals, travels to Vladivostok, the port city close to Japan [Figure 1], to obtain spare parts for their vehicles or second-hand Japanese cars, which many in Yakutsk prefer. Despite threats to ban the use of right-hand steering cars in Russia and to increase the tax on imported cars, drivers remain confident the Japanese cars will continue to be widely used in the country. Japanese models are reputed to be reliable, durable, and economical to drive in these northern conditions. Still some drivers travel all the way to Japan to hand-pick vehicles produced for the Japanese Domestic Market (JDM). These cars, unique in their design, are appreciated by the drifters for their powerful technology and suitability for drifting and racing purposes.

However, buying the car is not sufficient to make one's drifting dream come true; I heard many times from various drivers in Siberia that a good drifting car should be nurtured. To make a powerful rear-wheel-drive car perform drifting, heavy modifications and tuning of its original factory configuration are required. Unlike 'modding', light and insignificant modifications, in drifting the most significant configurations are carried out to the engine, weight of the car and the rear differential to increase the car's performance. In search of the optimal performance while drifting, the vehicles are often stripped to the original factory frame, while the inner parts of the future drifting car are taken from different cars or ordered on eBay. This is the core of 'domestication' or 'taming', as it were, the process when the car turns into a light but robust vehicle, safe and strong for potentially serious impact in an accident, yet predictable and obedient.

Assemblage is what turns a car into a drifting car and a driver into a drifting driver. As most drifters build their cars themselves or as a team, assembling the car creates a unique relationship between the owner and the car, thus endowing the latter with quasi-sentience (Roth 2014: 100). The term 'cyborg bodies' (Lupton 1999) refers to the inextricable collaboration between humans and their vehicles and is appropriate in this context. The term also underlines the most important aspect in such collaboration: knowledge of the vehicle. One needs to be sure in oneself, one's skill and, more importantly, the car. The car should be fixed to one's needs and requirements, almost like a well-tailored suit; this metaphor neatly conveys how drifters view their cars as parts 
of their extended bodies, prosthetics even (Dant 2004; Falconer and Kingham 2007; Lupton 1999; Sheller 2004). Simultaneously the vehicle is a partner: 'I feel the car very well and know how to get along', 'I understand the car and can hear it well'. Phrases like these expressed by drivers emphasise a 'driver-car assemblage' (Dant 2004) where the car and the driver complement each other, creating a symbiotic duet and where the car is endowed with profound agency. Ilia, a competitive racer, comments on the relationship with his sports car:

I always talk to my car when racing. After the race, when together with the team we analyse my driving recorded on the video, I ask to switch the sound off. It is kinda awkward (striomno) that I talk to her, you know. Last spring, I overturned during a race. I wanted to take over and failed, I regretted that of course. And there was my car, standing there, sad looking (pechal'naia). Nevertheless, she did two more rounds in such state. Screeching but running nevertheless. I kept talking to her: 'Just do this to the end and I will make it up for you, Little Swallow (Lastochka)'. That's how I call her. And look at her now - new bonnet, new side panels, new doors. She is a beauty [Figure 5]. 


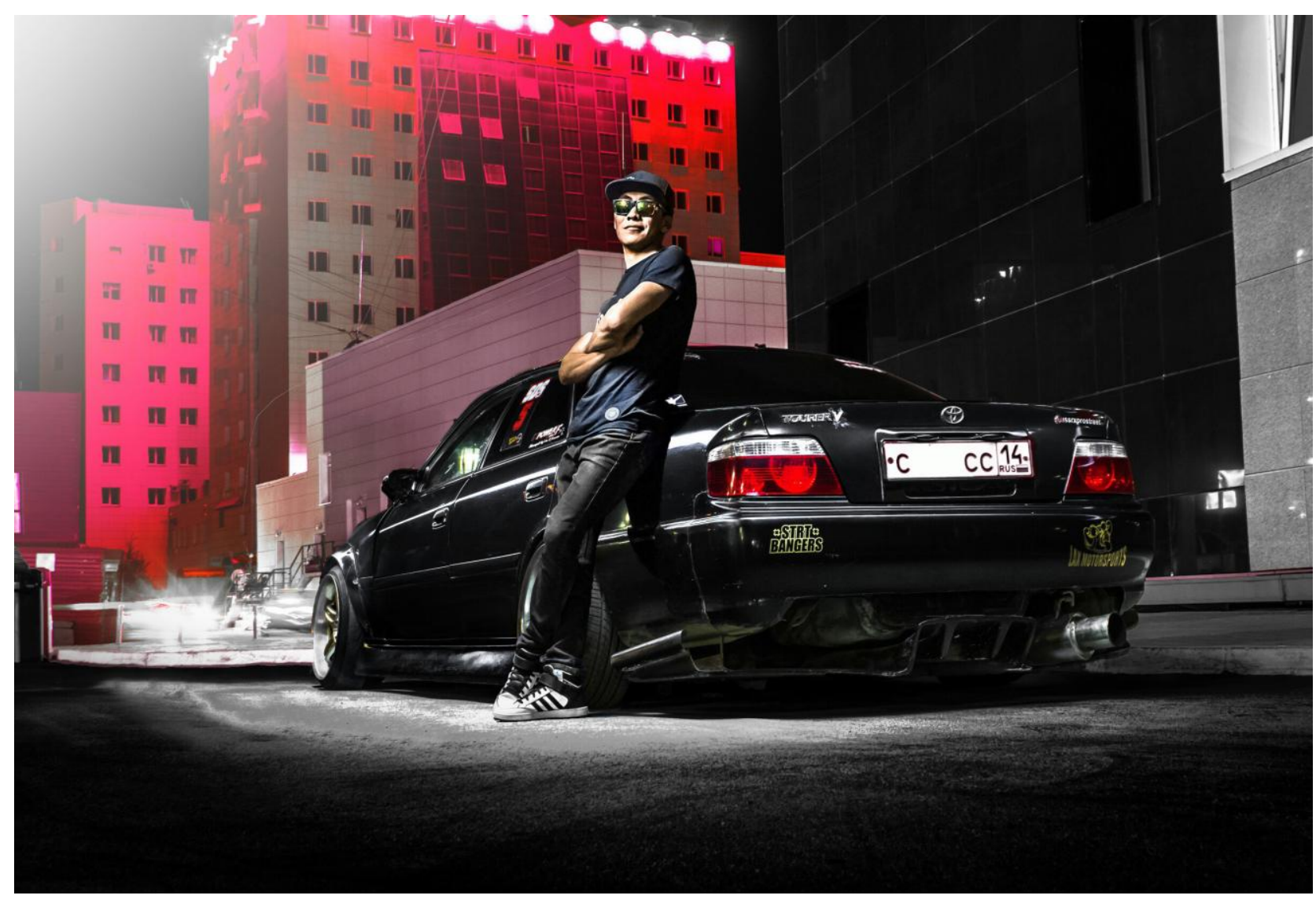

Figure 5. A young man and his car. (Photo: Ivan Struchkov)

This notion of partnership comes out strongly in the contrast between drift drivers and drag racers, who in conversations are often presented as less engaged and less intelligent drivers. Racers value speed the most, 'they just squeeze out what they can from the vehicle' (vyzhat'vse chto vozmozhno). Yet drifting, according to my interviewees, assumes greater reliance on the balance between the car's performance, which is complemented by the skill and intellect of the driver: 'one needs to think quickly, not only work with one's feet' (nado bystro golovoi dumat', a ne tol'ko nogoi rabotat') (cf. Dawson 2017a: 10-11). Together, the driver and the car enact well-practised stunts, a form of 'choreography'. As one informant eloquently described it: 'It takes two to drift'.

The culture of drifting that arrived in the Siberian city of Yakutsk from Tokyo and Hollywood has clearly demonstrated multiple cultural entanglements in the global space. It is also apparent, the influence from Japan 
related to contemporary car cultures with its advanced technology and automobile practices in this part of Russia, is profound. The proximity of Japan intensifies the influences that become tangible in Yakutsk. The ideas and notions about drifting that travelled from Japan with films, cartoons and YouTube clips inspired many young men in Yakutsk to adopt drifting techniques and to borrow the ideas, but this was not a mere replication or blind copying. These foreign ideas were localised to suit the needs of the city youth, who domesticated their dreams.

\section{Simulacra and the Freedom of the Road}

Engaging with the reality on the screen transfers people to other places in virtual space, the process that John Urry (1999) referred to as 'weightless travel', which in this paper seems to have a straightforward correlation. Indeed, the film Tokyo Drift transported young people in Yakutsk to Japan to virtually experience speed, to sense risk and victory over the yakuza gang. However, there is more to such a simple and blunt correlation. The complex interrelation and intertwining of virtual and real that Baudrillard points to (1988), in his search of America's empty freeways and desert speed, is important for this analysis. The weightless mobility of the film has increased the longing for corporeal travel in Yakutsk. The film reduced the distance between what was portrayed on the screen and helped to change reality for these young men.

Baudrillard (1988) viewed the screen, television and film as more than just pure reflections of real life. His term 'simulacra' refers to the signs and symbols in our life that have replaced the real things, making our experience of life (to a point) a simulation of reality. Simulacra are reproductions, copies, duplicates and replicas, but while created on the basis and acknowledgement of an existing original, they are beyond copies of the real. Such simulacra are objects and phenomena in their own right. They are hyperreal. Films are then hyperrealities, originally inspired by a real event or action and then developed into a reality in their own right. The gap between the cinema and reality becomes narrow; the coexistence of reality with hyperreality, where the latter is an exaggerated reality, where one notion slips into the other and where the meanings of both coalesce and blur (3). Although activities on the screen happen in a concrete place and events retain references to actual sites, these real places assist in the creation of hyperreality, a simulacrum. When we, the viewers, 
watch such activities on the screen, we give ourselves an account that the high-octane street racing, despite occurring on the well-known streets in Tokyo, is nevertheless hyperreal and is unlikely to happen during our next visit to Japan.

Baudrillard's transference from real to hyperreal can be taken one step further. The hyperreality of the screen undeniably affected many youngsters in Russia (Pilkington 2003: 329-331). Such back-to-real-life transference of screened hyperreality brings an altered dimension to reality. An alternative reality, a make-believe world, is often created by young people, for example through dangerous driving on the streets of Kyoto (Sato 1991: 147). Often such alternative reality is expressed with grotesqueness and exaggerations, such as roaring exhaust pipes, over-zealously performed stunts, extravagant car modifications, the paintwork, and embellishments [Figure 6]. Such transference of virtual hyperreality into reality helps to create its own 'communities of belonging, as celebrations of tolerance and egalitarianism, as extraordinary places for freedom of selfexpression, and most importantly, as refreshing, multifaceted "difference" from the commercialised mainstream' (Hanlon 2006: 36). 


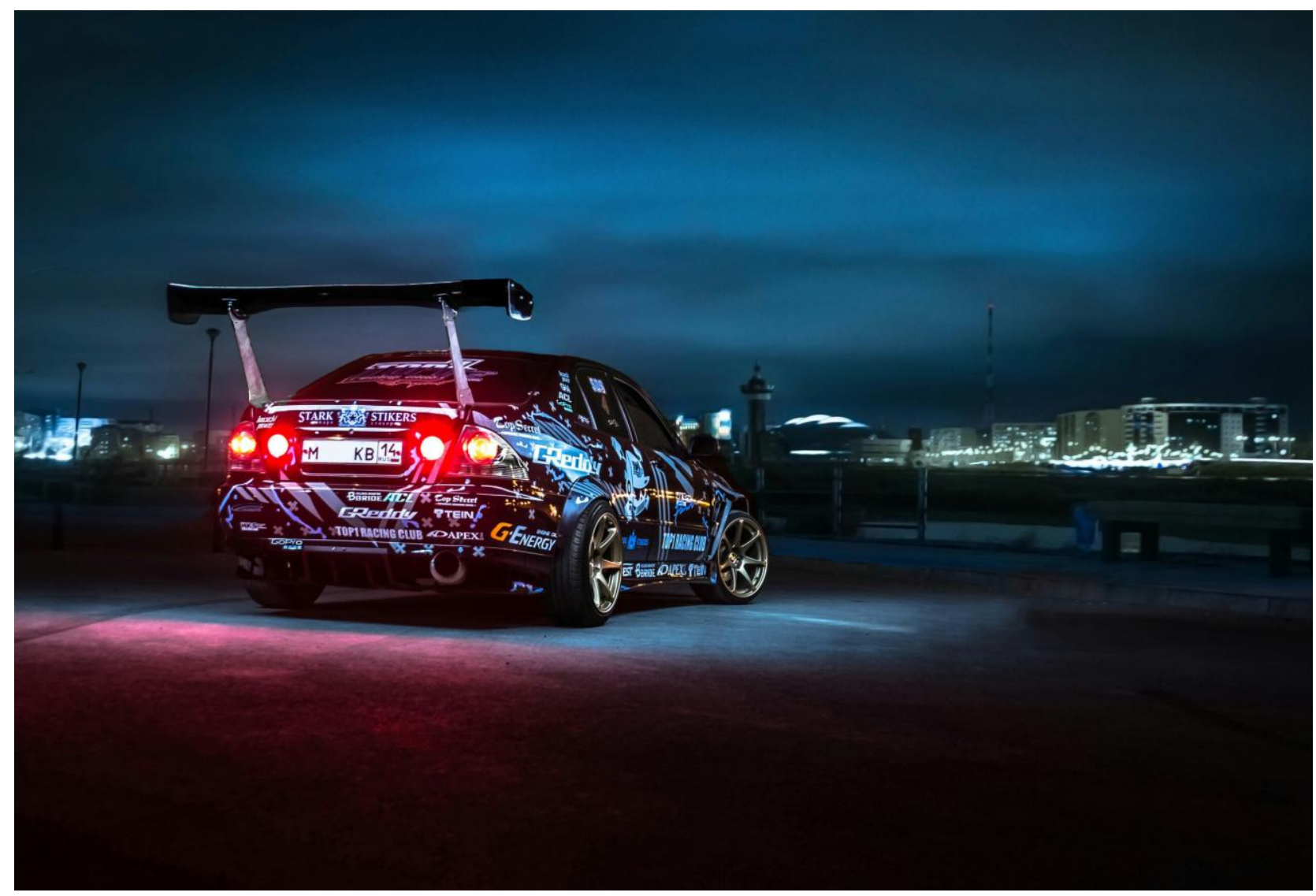

Figure 6. An embellished car. (Photo: Ivan Struchkov)

For many young men in Yakutsk, Tokyo Drift served as an inspiration for car stunts, driving styles and actions. But in the process of copying, these young drifters have clearly created their own space. Indeed, 'simulation threatens the difference between the "true" and the "false", the "real" and the "imaginary" (Baudrillard 1994: 3). What comes out as the result of transferring simulations and blurring of hyperrealities with realities, is the creation of new space, productive and strategic, responsive to the agendas and demands of these young men. In this new generated space, the young men in Yakutsk can perform drifting and racing.

Formal roads are the most regulated spaces, which are marked by manifestation of dominance and power (Foucault 1984; 1991; Merriman 2007). Road users should conform to the rules stipulated by signposts, indication of speed restrictions, traffic lights, and speed cameras. A road is a controlled space where otherwise idiosyncratic ways of driving are not tolerated. Speeding and drifting are often perceived as anti-social behaviour and associated with crime and deviance (Bengry-Howell and Griffin 2007; Falconer and Kingham 
2007; Lumsden 2015; Sato 1991; Vaaranen 2004; Vingilis and Smart 2009). Indeed, the young drift drivers feel they have been treated with suspicion and criminalised a priori because of their hobbies and the types of cars they drive. Some drift drivers in Yakutsk recount they are often first to be questioned after accidents involving an unknown perpetrator, due to their association with drifting groups. Indeed, research by some scholars confirms such criminalisation of the car subcultures is often constructed, and the young drivers are stigmatised (Chappell 2006: 51-62; Sato 1991: 3-5).

Yet some anthropological studies demonstrate that such aggressive behaviour and violence on the roads are reactions to roads and highways being controlled spaces, hence these sites are used for expressing opposition (Dalakoglou 2010; Harvey and Knox 2015; Roseman 1996; Yazici 2013). Drifters often use the road space to express their non-conformity and resistance by subverting rules. While some members of drift clubs do not approve of such behaviour, for some young men the very existence of rules is often considered an opportunity to flout them. They can brazenly race on public roads, seeing speed as the best way to upset the discipline of social order. For these young men, the act of breaking the rules and being chased by the police or simply sticking out from the crowd (vysovyvat'sia iz tolpy), as one informant expressed it, is a way to suspend rules and sense the freedom of the road. For example, Misha acknowledged his interest in this hobby was about speed, risk, and dangerous driving. Misha was not afraid to confess his dangerous driving to me, describing himself as 'risky' (riskovyi ia).

\footnotetext{
We used to practise 'races without rules' as they were called (gonki bez pravil). We were supposed to get from one end of the town to another in the fastest possible time. Taking different shortcuts, various routes and racing along the road of course. No rules. To get there some occasionally did 'chess driving' ( $v$ shakhmaty igraesh') and all kinds of risky stunts. The winner would get the jackpot of money. Oh yes, we annoyed and scared all other drivers [he grinned].
}

The perception of the road as a space where restrictions can be broken has been intensified with the help of the cinema and in the process of transference of the cinematic experience into real life. As in Baudrillard's (1988) formula where simulation precedes the real, The Fast and the Furious: Tokyo Drift served as an inspiration and 
has given an urge to many young people to replicate the portrayed style of fast driving and engagement with the road. Such perspective projected through the cinema created a perception of the road as a free space, space without boundaries and suspended rules. The screened reality altered perception of the conventional road.

Emotions are an intrinsic part of driving which heighten and intensify the experience, as Pink et al (2017), Roth (2012), and Yazici (2013) argue. For instance, Andrew Dawson (2017a; 2017b) argues against the idea of driving as disengagement in an enclosed space of the car. In the post-socialist Bosnia, driving is a sensory experience (2017a). 'Driving is replete with affect,' Bishara says succinctly (2015:36), with reference to driving in Palestine. Emotions of anger and aggressive behaviour as part of driving has been discussed by Redshaw (2008: 134). Risky and dangerous driving is similar to what Sato describes as 'outlet of emotions' (Sato 1991: 15). Experiencing freedom in driving is at the core of the Tokyo Drift. A phrase from the film voiced by a central character of The Fast and the Furious captures it evocatively: 'I live my life a quarter-mile at a time. Nothing else matters: not the mortgage, not the store, not my team and all their bullshit. For those ten seconds or less, I'm free' (The Fast and the Furious 2001). The understanding of the road in this sense is also expressed in Jack Kerouac's On the Road. The road becomes a different space, 'the other space' that is used to affirm difference and an escape from dominant authoritarianism (Foucault 1997). The temporal dimension of such experiences of freedom is critical for further development of my argument. During the night in Yakutsk, the young men practise their skills while the city is resting. They are creating a road space of freedom in an environment that continues to be characterised by domination and control, for liberty and freedom do not happen automatically, according to Foucault. 'Liberty is a practice...' (Foucault 1984: 245). For drifters in Yakutsk, such a notion of liberty is increasingly restricted, as roads are becoming more controlled by police and the CCTV cameras. The drifters feel the pressure of sticking to certain areas that are still free from surveillance. A certain kind of road space is produced as a result, as discussed in the next section.

\section{Heterotopia of the road}

Most of the informal drift sessions and drag races in Yakutsk took part during the night, when the streets were virtually empty, minimising the chance of accidents, disturbance and police interference (cf. Vingilis and 
Smart 2009). Only during night hours can the drifters perform their stunts in the outskirts [Figure 7].

Occasionally, some drifters charge along the smooth stretches of main streets with a mighty roar, as did a drifter from St Petersburg called Borshch, who audaciously performed drifting on St Isaac's Square at night (4).

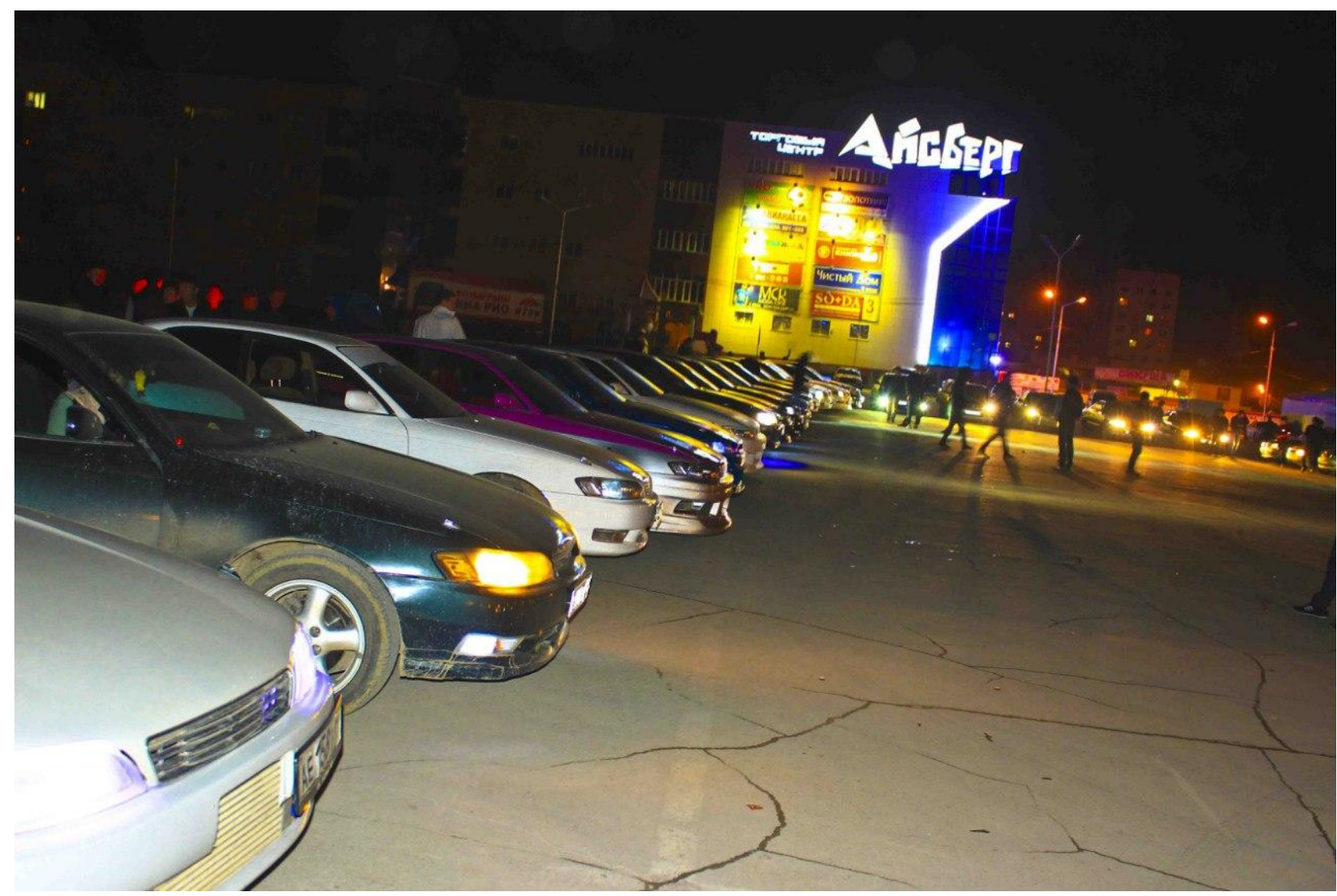

Figure 7. Getting ready for a drifting session. (Photo: Ivan Struchkov)

Night-time has liminal and marginal aspects (Schnepel 2006; Gallan 2015). Resulting from the opportunities the night offers, the road turns into a new space, filled with a sense of risk, speed and adrenalin. Such spaces, as Foucault expresses it succinctly, are: 'real and effective spaces ... in which all the real arrangements, all the other real arrangements that can be found within society, are at one and the same time represented, challenged, and overturned: a sort of place that lies outside all places and yet is actually localizable' (Foucault 1997: 332). Such spaces are connected with all other spaces but also contradict them. Foucault terms them heterotopias (1997), without much specification and sometimes fleetingly, luring readers 'to suggest a range of exciting possibilities' (Edensor 1998: 218). 
Heterotopias are 'concrete technologies' (Faubion 2008: 33). The ordinary and pervasive road taken for granted and along which people habitually drive to work, during the night turns into a road space written according to 'another set of scripts ... of aggression, competition and speed' (Urry 1999: 12). The night road becomes a place which is feared, even forbidden for some people. The road, while familiar, at the same time can exist as alien and foreign, as a reflection in the mirror (Foucault 1997). Thus, roads obtain heterotopic qualities due to alternative perspectives of the road space, the propinquity of road safety with imminent threat and danger, and because of its temporal framing. The road emerges as a form of heterotopia through the attribution of meanings and significance, and through the process of engaging with it. Importantly, as Michel Foucault states, it is relationships that matter: 'We do not live in a sort of a vacuum, within which individuals and things can be located ... but in a set of relationships that define positions which cannot be equated or in any way superimposed' (1997: 331). It is therefore the relationship with the cinema, cars, urban space and also with speed and freedom that changes the road, its meaning and its perception for the drift drivers. The heterotopia of the road is then a product of understanding and engagement with space. It can be argued that such heterotopia has an intrinsic quality and exists at all times but emerges only in situations where given conditions of the space allow it to be revealed to the users of the space. It is therefore possible that an old road that is used by conventional road users has never manifested its dormant heterotopic qualities to them. Yet when other users of the road bring out an alternative perspective and aspects of use, the road emerges to its users as a totally different kind of space with clear heterotopic dimension.

Entry into the road as a space for drifting, racing and fast moving is not open to everyone, however. The affinity the members of drifting clubs share with access codes, specific knowledge and secrecy creates the heterotopia of the road (Cenzatti 2008: 82). The drifters have to execute caution about their gatherings, as street racing and drifting on public roads are illegal. It took me some time to arrange an initial interview with some drifters; my unsolicited interest in their activities was treated with an element of suspicion. The text messages sent around with the details of the next drifting sessions were cryptic (cf. Vingilis and Smart 2009). The use of the road during the night creates a certain vision and understanding of the road, different from the perception of customary road users. The road at night becomes a space with restricted access; it opens up only to people who have specific knowledge, skills or perspectives, as heterotopias 'always presuppose a system of 
opening and closing that isolates them and makes them penetrable at one and the same time' (Foucault 1997: 335). Foucault adds that one can enter such heterotopias only 'by special permission and after one has completed a certain number of gestures' (ibid).

For many drifters, such a practice is an opportunity to counter-balance the lack of recognition elsewhere (Vaaranen 2004). Drifting helps to build their own social circle while engaging in a new, creative driving performance. It is also a ritual of 'coming-of-age', as many drifters are between leaving school and starting a serious professional career. Many drifting enthusiasts maintain their day jobs as clerks, security guards, occasional drivers, to support their rather expensive hobby of drifting, and devote the night-time to their passion. They find themselves in a heterotopic space framed temporally by their youth and by the marginality of night. Young people are consumers of the night-time, and their experiences in the night-time create a different involvement, not comparable with their everyday experiences.

Why is it important to acknowledge the road as a form of heterotopia? Maybe because heterotopia makes us understand the road, as a concept, better? Or maybe because it helps demonstrate that a road is more than just a physical connection between two points? All of the above applies, but more significantly, because heterotopia makes the complex connections more tangible and highlights important social connotations a road has for the young people who use it to express themselves. Roads, as I have suggested elsewhere, are social phenomena (Argounova-Low 2012a). Acknowledging the heterotopic nature of the road highlights such social aspects, recognising that people's perceptions of the road can be different, even if marginalised, and their experiences of the road can be diverse. It also highlights multiple, and often contradictory, visions, understandings and uses of roads. Heterotopia becomes a very useful tool for analysis, not just as a spatial concept, but as a framework in which to formulate and expand on the notion of the road in anthropological studies.

The perception of the roads, bridges and railways as purely hardware infrastructure are now becoming untenable. With predictable duality, hard infrastructures are opposed to soft or cultural infrastructures that refer to intellect, imagination, venues for creativity, music, as demonstrated by Gallan (2015) and Landry (2006). Meanwhile Dalakoglou and Harvey (2012), Harvey and Knox (2015), Dawson (2015) have all pointed out the role roads play in ideological, political and memory work, emphasising that roads are more than technological systems, and comprise sensorial and aesthetic dimensions, cultural meanings and fantasy (Larkin 2013). I 
argue against the simplistic distinctions made between hard and soft infrastructures and demonstrate that road space is far from just a transport link. The case study presented here highlights the global connections of social engagements with the road, demonstrating how inspiration from films, cartoons, and video games instigate drift drivers in Siberia who use this road space for their performative and social engagements [Figure 8]. This aspect is emphasised by the Japanese touge roads, with their hairpin turns that served as an encouragement for creation of a new and ingenious style of driving and the upsurge in the vast genre of comic series and films devoted to drifting. With the research material discussed here, in the context of Yakutsk, I argue that roads are not just lacklustre hardware infrastructure. Roads are indeed very clearly part of cultural infrastructure and a spectacular cultural space that provide room for self-expression, creativity, and freedom.

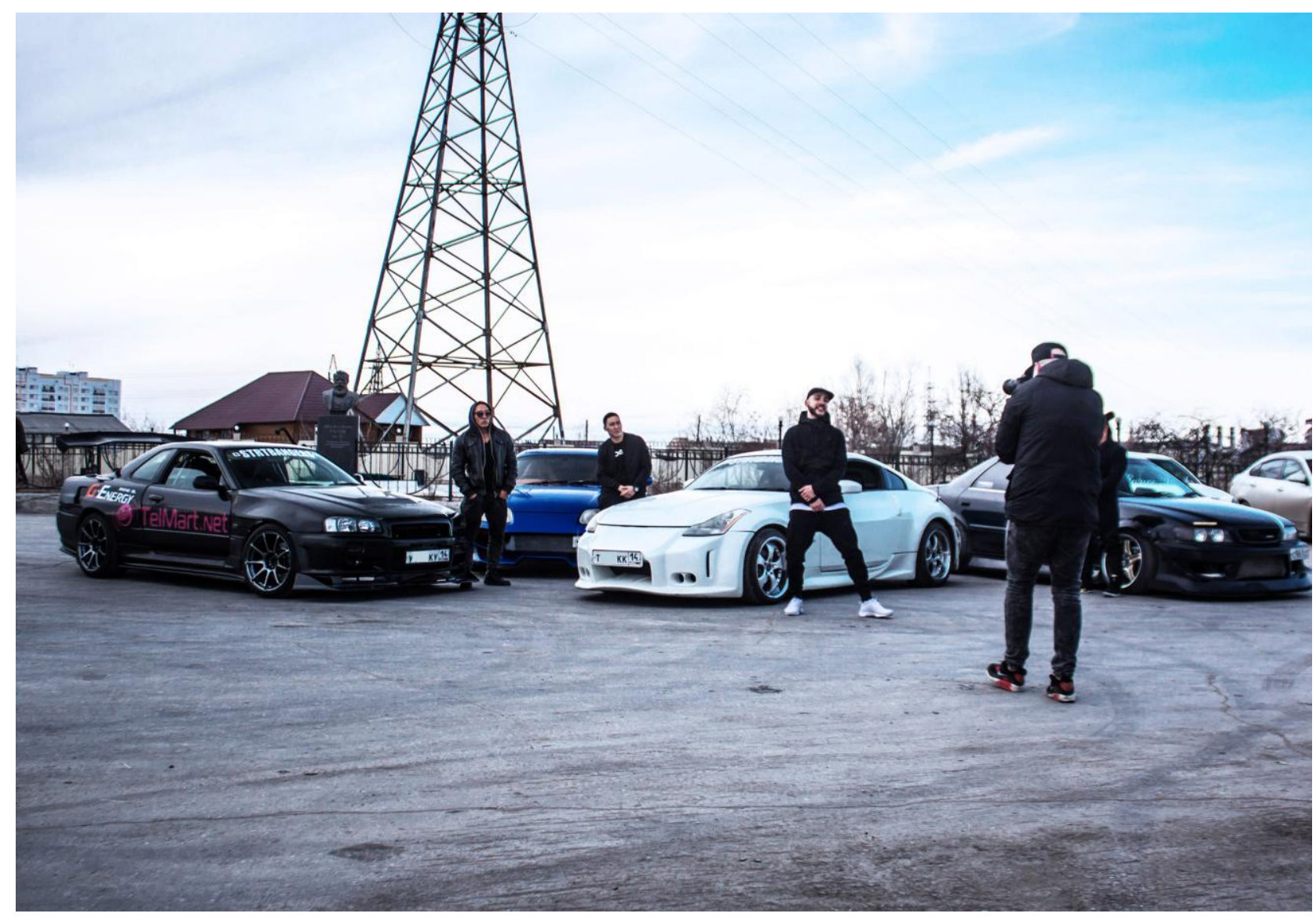

Figure 8. A photographic session with cars. (Photo: Ivan Struchkov) 


\section{Conclusion}

This paper focuses on expanding car cultures in Sakha (Yakutia), north-eastern Russia, influenced by the proximity of Japan. Together with the imported second-hand cars and spare parts for automobiles delivered from across the Sea of Japan, arrive to Yakutsk car fashions, trends and inspiration for car enthusiasts. Drifting is one such fashion and a special driving technique. It originated as an illegal racing along touge, the hilly winding roads in Japan. The article demonstrated how this driving technique, popularised through various outlets such as the animation films, YouTube and blockbuster film The Fast and the Furious: Tokyo Drift, was embraced by the drift driving enthusiasts in Yakutsk.

Drift driving is a fashion, a hobby and a sport. To achieve their sporting ambitions, drift drivers amend their cars, originally delivered from Japan, and tailor them further for their own specifications. In the process of modification, the cars become extensions of their owners, as well as reliable partners. It is both a process of taming of foreign cars and a process of domestication of ideas and dreams, I argue. Such transference of trends and influences from across the Sea of Japan and Hollywood to Siberia, highlights the shifting geographies and multiple social, cultural and technological connections.

While young people in Yakutsk use the Hollywood film Tokyo Drift as an inspiration for car stunts and driving styles, in the process of copying, they create their own space blurring fantasies and realities. The result is a new hyperreality, productive and strategic space, responsive to their agendas and demands. In this new generated space, the drivers in Yakutsk perform drifting and racing.

The post-Soviet space with its increased mobility provided an opportunity for energetic development of car cultures. Jean Baudrillard's analysis of post-war America provides a parallel with the post-Soviet space and helps to highlight a shift from the rigid and enclosed ideological and physical space. Contemporary Russia is gradually opening its borders and moving away from the sedentarism of the Soviet Union that for many 
decades denied people's mobility. The Communist past and memories associated with stagnation and fixity are replaced by motion and dynamism. The space that emerges in the process of increased pace of life, termed 'desert' by Baudrillard, is characterised by practicality and pragmatism. The fast pace of life and increased driving, 'desert speed' as Baudrillard calls it, helps discover the new and forget the old. Driving is a crucial element in this process as it is 'a spectacular form of amnesia. Everything is to be discovered, everything to be obliterated' (Baudrillard 1988: 10).

Formal roads are heavily regulated spaces and are marked by manifestation of dominance and power (Foucault 1984; 1991; Merriman 2007). Road are controlled spaces where speeding and drifting are perceived as antisocial behaviour and linked to crime and deviance. Yet drift drivers use this space to express their appreciation of speed and to experience freedom. Lack of good racing tracks constricts their opportunities for excelling in this kind of sport, and the members of drifting clubs are forced to practise illegally, usually during the night, on roads in the city, forever avoiding police. They pursue speed and movement to subvert the order and to sense freedom on the road.

I argue that the road is a useful analytical category, in anthropological studies. Road becomes a tool and a prism allowing a more detailed investigation of spatial engagement that otherwise might be ignored or omitted. Roads are more than hard infrastructures operating on fixity, structure and hardware. Roads, I suggest, are soft infrastructures and serve as creative spaces that are important to produce the whole new range of artistic work: manga series, animation or feature films, and sporting achievements. Roads have become a space conducive to creative engagements. Such alternative visions of the road produce a new space in Yakutsk. A controlled and regulated road during the day becomes a space filled with speed and force during the night. For ordinary road users, this is a forbidden space with no access. Such a road at night, following Foucault, becomes a heterotopic space. Indeed, as this study demonstrates, familiar and well-explored roads can become alien. It is simultaneously a space we recognise and yet we do not. Foucault's image of heterotopia is the mirror that reflects real and familiar space and yet it is unreal and unfamiliar. With the similar imagery in mind, road, too, becomes a heterotopia. Standing in front of the window and looking on the road, we recognise it and yet the loud screeching noise, and clouds of smoke coming from underneath the wheels turn it into heterotopia. And the road, like a reflection in the mirror, will remain on the other side. 


\section{NOTES}

I would like to thank colleagues at Aberdeen who discussed earlier drafts of this paper, anonymous reviewers for their pertinent comments. I am grateful to Ivan Struchkov for images. Many thanks to drift drivers in Yakutsk who helped with this research, especially Dmitrii and Sasha.

1. All real names have been changed.

2. Silverstone is a motor racing circuit near Northampton and Milton Keynes, England. It is dubbed "The home of British motor racing".

3. For illustration see Sato (1991:77) where youths in Japan copy actions from a film, paying more attention to the automobile paraphernalia than the plot of the film.

4. The YouTube video received great attention among the drifters. It was also shown in the news (https://www.youtube.com/watch?v=gkvHV4GHTss).

Dr Tatiana Argounova-Low is Senior Lecturer in Anthropology at the University of Aberdeen, United Kingdom. Her research focuses on mobility, movement, and driving. She conducts her fieldwork in the northern regions of Russia. Her recent publications highlight the role of roads in anthropology.

Address: Anthropology, School of Social Science, University of Aberdeen, Aberdeen, AB24 3QY, United Kingdom, t.argounova-low@abdn.ac.uk 


\section{REFERENCES:}

Archer, N. 2017. Genre on the road: The road movie as automobilities research. Mobilities 12:4, 509-519.

Argounova - Low, T. 2012a. Narrating the road. Landscape Research 37(2), 191-206.

Argounova - Low, T. 2012b. Roads and Roadlessness: Driving Trucks in Siberia. Journal of Ethnology and Folkloristics 6(1), 71-88.

Baudrillard, J. 1988. America. Translated by Geoff Dyer. London: Verso.

1994. Simulacra and simulation. Translated by S. Glaser. Ann Arbor: University of Michigan

Press.

Belov, A. 2005. Regional dimensions of economic cooperation between Japan and Russia. Journal of EastWest Business 11(1-2), 119-140.

Bengry-Howell, A. \& C. Griffin 2007. Self-made motormen: the material construction of working-class masculine identities through car modifications. Journal of Youth Studies 10 (4): 439 - 58.

Bishara, A. 2015. Driving while Palestinian in Israel and the West Bank. American Ethnologist 42 (1), 33-45.

BOFIT Weekly. 2017. Number of passenger cars on the road in Russia rises from 26 million to 45 million in just ten years. https://www.bofit.fi/en/monitoring/weekly/2017/vw201711_2/. Accessed 25 July 2019.

Cenzatti, M. 2008. Heterotopias of difference. In: Heterotopia and the city: public space in a postcivil society (eds.) M. Dehaene and L. De Cauter, 75-86. London: Routledge.

Chappell, B. 2006. Lowrider cruising spaces. In Mobile crossings: representations of Chicana/o cultures (eds.) A. Bandau and M. Priewe, 51-62. Trier, Germany: Wissenschaftlicher Verlag Trier. 
Cresswell, T. 1993. Mobility as resistance: a geographical reading of Kerouac's 'On the road'. Transactions of the Institute of British Geographers (N. S.) 18(2), 249-62.

Dant, T. 2004. The driver-car. Theory, Culture, Society 21(4-5), 61-79.

Dalakoglou, D. 2010. The road: An ethnography of the Albanian-Greek cross-border motorway. American Ethnologist 37(1), 132-149.

Dalakoglou, D. \& P. Harvey (eds.) 2012 Roads and Anthropology: Ethnographic Perspectives on Space, Time and (Im)Mobility, Mobilities, 7(4).

Dawson, A. 2015. The road to Srebrenica: Automobility and belonging in a post-socialist/war milieu. Anthropological Notebooks, 21(1), 5-25.

Dawson, A. 2017a. Driven to sanity: An ethnographic critique of the senses in automobilities. The Australian Journal of Anthropology 28 (1), 3-20.

Dawson, A. 2017b. Why Marx was a bad driver: Alienation to sensuality in the anthropology of automobility. Advance in Anthropology 7, 1-16.

Edensor, T. 1998. Culture of the Indian street. In Images of the street (ed.) N.Fyfe, 205-221. London: Routledge.

Eyerman, R and O. Löfgren. 1995. Romancing the road: Movies and images of mobility. Theory Culture Society $12,53-79$.

Falconer, R. \& S. Kingham 2007. 'Driving people crazy': a geography of boy racers in Christchurch, New Zealand. New Zealand Geographer 63, 181-191. 
Faubion, J. 2008. Heterotopia: an ecology. In Heterotopia and the city: public space in a postcivil society (eds.)

M. Dehaene, L. De Cauter, 31-41. London: Routledge.

Federatsiia avtomobil'nogo i mototsikletnogo sporta Respubliki Sakha (Yakutia) [Federation of the automobile and motorcycle sport of the Republic of Sakha (Yakutia)] http://fams14.ru/. Accessed 5 July 2019.

Foucault, M. 1984. Space, knowledge, and power. In P. Rabinow (ed.) The Foucault Reader. New York: Pantheon Books, 239-56.

Foucault, M. 1991. Governmentality. In G. Burchell, C. Gordon and P. Miller (eds) The Foucault Effect: Studies in Governmentality. Hemel Hempstead: Harvester Wheatsheaf, 87-104.

Foucault, M. 1997. Of other spaces: utopias and heterotopias. In Rethinking architecture: a reader in cultural theory (ed.) N. Leach, 330-336. New York: Routledge.

Gallan, B. 2015. Night lives: heterotopia, youth transitions and cultural infrastructure in the urban night. Urban Studies 52(3), 555-570.

Hanlon, K.B. 2006. Heavy metal carnival and dis-alienation: the politics of grotesque realism. Symbolic Interaction $29(1), 33-48$

Harvey, P. 2012. The topological quality of infrastructural relation: an ethnographic approach. Theory, Culture and Society 29:4-5, 5-26.

Harvey, P. \& H. Knox 2012. The enchantments of infrastructure. Mobilities 7(4), 521-536.

Harvey, P. \& H. Knox 2015. Roads: An anthropology of infrastructure and expertise. Ithaca: Cornell University Press.

Katsu, T. 2003. The Drift Bible. Documentary. Duke Video. 
Kerouac, J. 1957. On the road. Harmondsworth: Penguin.

Kruglova, A. 2019. Driving in terrain: Automobility, modernity, and the politics of statelessness in Russia. American Ethnologist 46 (4), 457-469.

Kusunoki, M. 1993. Wangan Midnight. Tokyo: Kodansha.

Landry, C. 2006. Lineages of the creative city. Research Journal for Creative Cities 1, 15-23.

Larkin, B. 2013. The politics and poetics of infrastructure. Annual Review of Anthropology 42, 327-343.

Larson, L.E. 2009. Free ways and straight roads: The interstates of Sal paradise and 1950s America. In What's Your Road, Man? Critical Essays on Jack Kerouac's “On the Road” (eds.) H. Holladay and R. Holton, 35-59. Southern Illinois University Press.

Lefebvre, H. 1971. Everyday life in the modern world. London: Allen Lane.

Lumsden, K. 2015. (Re)civilizing the younger driver: technization and emotive automobility. Mobilities 10 (1), $35-54$.

Lupton, D. 1999. Monsters in metal cocoons: 'road rage' and cyborg bodies. Body and Society 5(1), 57-72.

Merriman, P. 2007. Driving spaces: a cultural-historical geography of England's M1 motorway. Oxford: Blackwell Publishing.

Mills, K. 2006. The road story and the rebel: Moving through film, fiction, and television. Carbondale: Southern Illinois University Press.

Mom, G. 2005. Roads without rails: European highway-network building and the desire for long-range motorized mobility. Technology and Culture 46(4), 745-772. 
Official Government Portal. Government of the Republic of Sakha (Yakutia). https://www.sakha.gov.ru/orespublike-saha--kutiya-/obschiesvedeniya

Pilkington, H. 2003. Youth and popular culture: The common denominator. In Russia and Western civilization: Cultural and historical encounters (ed.) R. Bova, 319-350. London: Routledge.

Pink, S., V. Fors \& M. Glöss 2017. Automated futures and the mobile present: In-car video ethnographies. Ethnography. On-line https://journals.sagepub.com/doi/full/10.1177/1466138117735621

Popov, V. 2012. The culture of new mobility in Russia: Networks and flows formation. Mobilities 7:1, 151169.

Poster, M. 2002. Everyday (Virtual) Life. New Literary History 33:4, 743-760.

Pozharliev, L. 2016. Collectivity vs. connectivity: Highway peripheralization in former Yugoslavia (1940s1980s). The Journal of Transport History 37:2, 194-213.

Redshaw, S. 2007. Articulations of the car: The dominant articulations of racing and rally driving. Mobilities $2: 1,121-141$

Redshaw, S. 2008. In the company of cars: Driving as a social and cultural practice. Aldershot: Ashgate. 
Roseman, S. 1996. "How we built the road": The politics of memory in rural Galicia. American Ethnologist 23(4), 836-860.

Roth, J.H. 2012. Heartfelt driving: Discourses on manners, safety, and emotion in Japan's era of mass motorization. The Journal of Asian Studies 71(1), 171-192.

Roth, J.H. 2014. Is female to male as lightweight cars are to sports cars?: Gender metaphors and cognitive schemas to recessionary Japan. In Vehicles: Cars, canoes, and other metaphors of moral imagination (eds.) D. Lipset and R. Handler, 88-110. New York: Berghahn.

Russian Drift Series https://www.facebook.com/rdsgrandprix/ Accessed July 2019.

Sato, I. 1991. Kamikaze Biker: Parody and Anomy in Affluent Japan. Chicago: The University of Chicago Press.

Schnepel, B. 2006. Strangers in the night: the making and unmaking of differences from the perspective of an anthropology of the night. In The making and unmaking of differences (eds.) R. Rottenburg, B. Schnepel, B. and S. Shimada, 123-44. New Brunswick: Transaction Publishers.

Sheller, M. 2004. Automotive emotions: feeling the car. Theory, Culture, Society 21(4-5), 221-42.

Sheller, M. \& J. Urry 2000. The city and the car. International Journal of Urban and Regional Research 24(4), 737-757.

Shevchenko, N. 2019. Meet the Russian drifter who beat the Japanese at their own game. Russia Beyond 7 June https://www.rbth.com/lifestyle/330475-russian-drift-sochi-autodrome-arkady-tsaregradtsev. Accessed 25 January 2019.

Shigeno, S. 1995. Initial D. Tokyo: Kodansha.

Siegelbaum, L. 2008. Cars for comrades: the life of the Soviet automobile. Cornell: Cornel University Press. 
The Fast and the Furious. 2001. Dir. R. Cohen. Universal Pictures.

The Fast and the Furious: Tokyo Drift. 2006. Dir. J. Lin. Universal Pictures.

Urry, J. 1999. Automobility, car culture and weightless travel: a discussion paper. Department of Sociology, Lancaster University, Lancaster LA1 4YN, UK. (available on-line:

http://www.comp.lancs.ac.uk/sociology/papers/Urry-Automobility.pdf)

Urry, J. 2000. Sociology beyond societies. Mobilities for the twenty-first century. Milton Park: Routledge.

Vaaranen, H. 2004. The emotional experience of class: interpreting working-class kids' street racing in Helsinki. Annals of the American Academy of Political and Social Science 595, 91-107.

Vaaranen, H. and N. Wieloch. 2002. Car crashes and dead end careers: Leisure pursuits of the Finnish subculture of the kortteliralli street racing. Young 10(1), 42-58.

Verdury, K. 1996. What was socialism and what comes next? Princeton: Princeton University Press.

Vingilis, E. \& R. Smart 2009. Street racing: a neglected area of research? Traffic Injury Prevention 10 (2), 148 156.

Waitt, G., T. Harada \& M. Duffy 2017. 'Let's have some music': Sound, gender and car mobility. Mobilities 12: $3,324-342$.

Yazıc1, B. 2013. Towards an Anthropology of Traffic: A Ride Through Class Hierarchies on Istanbul's Roadways, Ethnos, 78 (4): 515-542. 